\title{
ОЦЕНКА РИСКА РАЗВИТИЯ СТРУКТУРНО-МЕТАБОЛИЧЕСКИХ НАРУШЕНИЙ КОСТНОЙ ТКАНИ У ЖЕНЩИН, БОЛЬНЫХ САХАРНЫМ ДИАБЕТОМ 2 ТИПА
}

\author{
'Бардымова Т.П., 'Мистяков М.В., ${ }^{2}$ Цыреторова С.С., ${ }^{3}$ Швецова С.В.
}

'Иркутская государственная медицинская академия последипломного образования — филиал ФГБОУ ДПО РМАНПО Минздрава России, Иркутск

2ОГАУЗ «Иркутская городская клиническая больница №3», Иркутск

ЗФГБОУ ВО ИркУтскИй ГАУ именИ А.А. Ежевского, Иркутск

ЦЕЛЬ: разработать способ оценки риска развития структурно-метаболических нарушений костной ткани у женщин, больных сахарным диабетом (СД) 2 типа.

МАТЕРИАЛЫ И МЕТОДЫ: в исследование включено 73 женщины, больных СД 2 типа, без тяжелых коморбидных заболеваний и состояний из них $34-$ с сохраненной функциональной активностью яич-

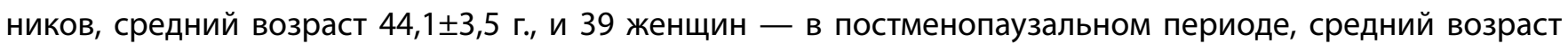
$58,2 \pm 4,2$ г. Группу сравнения составили 88 женщин без нарушений углеводного обмена, из них 46 жен-

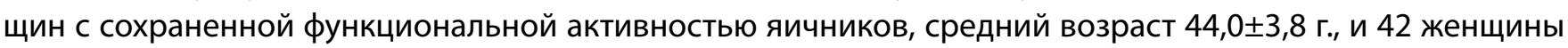

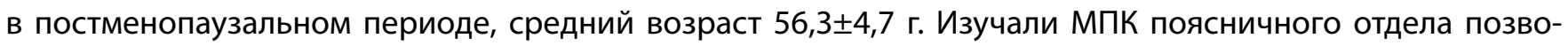
ночника, шейки бедра, проксимального отдела бедренной кости и трабекулярный костный индекс (ТКИ) методом двухэнергетической рентгеновской абсорбциометрии (аппарат Lunar Prodigy, General Electric, США). Дополнительно определяли показатели остеокальцина, С-концевых телопептидов коллагена I типа ( $\beta$-Cross laps), N-терминального пропептида проколлагена 1 типа (P1NP), витамина 25(OH) D, ионизированного кальция.

РЕЗУЛЬТАТЫ: методом проведенного дискриминантного анализа полученных в исследовании результатов выявлены наиболее информативные признаки, свидетельствующие о ранних изменениях костной ткани у пациенток с СД 2 типа, а также рассчитаны величины коэффициентов F1, F2, F3 и F4 по формулам:

$$
\begin{aligned}
& F 1=-203,307+3,384 \cdot X 1+0,664 \cdot X 2+0,050 \cdot X 3+163,659 \cdot X 4+0,469 \cdot X 5-23,776 \cdot X 5 ; \\
& F 2=-183,324+3,298 \cdot X 1+0,537 \cdot X 2+0,687 \cdot X 3+141,658 \cdot X 4+0,290 \cdot X 5-14,458 \cdot X 6 ; \\
& F 3=-247,826+4,174 \cdot X 1+0,872 \cdot X 2+0,258 \cdot X 3+159,068 \cdot X 4+0,447 \cdot X 5-19,092 \cdot X 6 ; \\
& F 4=-233,298+4,233 \cdot X 1+0,568 \cdot X 2+0,548 \cdot X 3+144,849 \cdot X 4+0,334 \cdot X 5-11,456 \cdot X 6,
\end{aligned}
$$

где: X1 - возраст, лет; X2 - уровень остеокальцина, нг/мл; Х3 - индекс массы тела, кг/м²; X4 - значение ТКИ; X5 - уровень Р1NP, нг/мл; X6 - уровень $\beta$-Cross laps, нг/мл.

Числовые характеристики коэффициентов F1, F2, F3 и F4 сравнивали между собой. Установлено, что при значении F1 больше F2, F3 и F4 оценивается низкий риск структурно-метаболических нарушений костной ткани, при величине F2 больше F1, F3, F4, а также при величине F3 больше F1, F2, F4 - промежуточный риск, а при величине F4 больше F1, F2 и F3 определяется высокий риск структурно-метаболических нарушений костной ткани. Точность оценки риска - 87\%. На основании полученных данных разработан способ оценки риска развития структурно-метаболических нарушений костной ткани у женщин, больных сахарным диабетом 2 типа (патент № 2703268, дата государственной регистрации 16 октября 2019 г.).

ВЫВоды: структурно-метаболические нарушения костной ткани у женщин, больных СД 2 типа, зачастую не имеют клинических проявлений, однако могут приводить к формированию диабетопороза, в том числе переломам костей. Использование предлагаемого технического решения позволяет оценить индивидуальный риск развития ранних структурно-метаболических нарушений костной ткани у пациенток с СД 2 типа независимо от возраста с проведением своевременных мер лечебного и профилактического характера.

КЛЮЧЕВЫЕ СЛОВА:сахарный диабет 2 типа; маркеры костного ремоделирования; денситометрия; трабекулярный костный индекс. 